\title{
Erkek İnfertilitesi ile Başvuran Hastalarda Spermiogram, Hormonal Profil ve Genetik Analiz Sonuçlarının Karşılaştırmalı Analizi: Tek Merkez Deneyimi
}

\author{
Alper GEZDİRİİ 國, Işık ÜNAL 國, Recep ERÖZ 國, Elif Yılmaz YILMAZ GÜLEÇ 國, \\ İbrahim Orkunt AYAZ ${ }^{5}$, Gülsemin ÇIÇEK ${ }^{2}$
}

\section{ÖZ}

Amaç: Bu çalışmanın amacı, hastanemize infertilite nedeniyle başvuran erkeklere yardımcı üreme tekniklerinden önce uygun genetik danışmanlık verebilmek için, azospermi ve/veya oligozoospermi etiyolojisine yönelik standart sitogenetik yöntemler ve Y kromozom mikrodelesyon analizleri ile hem majör kromozom anomalilerinin hem de Y kromozomu mikrodelesyonlarının sıklığı ve tiplerini araştırmaktır.

Gereç ve Yöntemler: Çalışmamıza 2017-2020 yılları arasında erkek infertilitesi nedeniyle Kanuni Sultan Süleyman Eğitim ve Araştırma hastanemize başvuran toplam 437 hasta dâhil edildi. Tüm hastalar spermiogram, hormonal profil, kromozom analizi ve $\mathrm{Y}$ mikrodelesyon analizleri doğrultusunda değerlendirildi.

Bulgular: Çalışmamızda toplam 437 hastanın 42'sinde $(\% 9,6)$ kromozomal anomaliler tespit edildi. En sık görülen kromozomal anomali 47,XXY(Klinefelter sendromu) idi. 5 hastamızda dengeli translokayonlar vardı. 1 hastada ise marker kromozom tespit edildi. Geriye kalan 395 hastanın kromozom analizi normaldi. 44 hastamızda $(\% 10,06)$ ise AZF genleri üzerinde çeşitli y-kromozomu mikrodelesyonları saptandı. 1 hastada AZFa delesyonu, 4 hastada AZFb $+\mathrm{c}$ delesyonu, 17 hastada AZF-c gr/gr delesyonu, 2 hastada komplet AZFa $+\mathrm{b}+\mathrm{c}$ delesyonu, 2 hastada komplet AZFc delesyonu, 1 hastada parsiyel AZFb delesyonu, 9 hastada kısmi AZFb+c delesyonu, 8 hastada parsiyel AZFc delesyonu tespit edildi. Geriye kalan 393 hastada herhangi bir Y kromozomu mikrodelesyonu saptanmadi.

Sonuç: Mevcut bilgiler ve geçmişteki literatür çalışmaları eşliğinde özellikle şiddetli oligospermi ve azospermili hastalarda kromozom analizi ve Y mikro delesyonu analizlerini yardımcı üreme tekniklerinden önce önermekteyiz.

Anahtar Kelimeler: Erkek infertilitesi; azospermi; kromozom anomalileri; Y kromozomu mikrodelesyonu.

\section{Comparative Analysis of Spermiogram, Hormonal Profile and Genetic Analysis Results in Patients Applying with Male Infertility: A Single Center Experience}

\begin{abstract}
Aim: The aim of this study is to investigate types of both major chromosomal abnormalities and Y-chromosome microdeletions by examining with standard cytogenetic methods and Y-chromosome microdeletion analyzes for azoospermia and / or oligozoospermia etiology to provide appropriate genetic counseling to men admitted to our hospital due to infertility before assisted reproductive techniques.

Material and Methods: A total of 437 patients who admitted to our Kanuni Sultan Süleyman Training and Research Hospital due to male infertility between 2017 and 2020 were included in our study. All patients were evaluated according to spermiogram, hormonal profile, chromosome analysis and Y microdeletion analysis.

Results: In our study, chromosomal anomalies were detected in 42 of 437 patients (9.6\%). The most common chromosomal anomaly was 47, XXY (Klinefelter syndrome). 5 of our patients had stable translocation. Marker chromosome was detected in 1 patient. Chromosome analysis of the remaining 395 patients was normal. Various y-chromosome microdeletions on AZF genes were detected in 44 patients (10.06\%). AZFa in 1 patient, $\mathrm{AZFb}+\mathrm{c}$ in 4 patients, $\mathrm{AZFc}$ gr / gr in 17 patients, complete $\mathrm{AZFa}+\mathrm{b}+\mathrm{c}$ in 2 patients, complete AZFc in 2 patients, partial $\mathrm{AZFb}$ in 1 patient, partial $\mathrm{AZFb}+\mathrm{c}$ in 9 patients, and partial $\mathrm{AZFc}$ were detected in 8 patients. No Y chromosome microdeletions were detected in the remaining 393 patients.
\end{abstract}

\footnotetext{
1 Başakşehir Çam ve Sakura Hastanesi, Tıbbi Genetik, İstanbul, Türkiye

2 Kanuni Sultan Süleyman Eğitim ve Araştırma Hastanesi, Histoloji ve Embriyoloji, Üremeye Yardımcı Tedaviler Merkezi, İstanbul, Türkiye

3 Düzce Üniversitesi Tıp Fakültesi, Tıbbi Genetik, Düzce, Türkiye

4 Kanuni Sultan Süleyman Eğitim ve Araştırma Hastanesi, Tıbbi Genetik, İstanbul, Türkiye

5 Kanuni Sultan Süleyman Eğitim ve Araştırma Hastanesi, Üroloji, İstanbul, Türkiye
} 
Conclusion: In the light of current information and past literature studies, we recommend chromosome analysis and y-micro deletion analysis, especially in patients with severe oligospermia and azoospermia, before assisted reproductive techniques.

Keywords: Male infertility; azoospermia; chromosomal abnormalities; Y chromosome microdeletion

\section{GIRIS}

Infertilite, genellikle bir çiftin bir yıl korunmasız, sık cinsel ilişkiye rağmen gebelik oluşturamaması olarak tanımlanır. Erkek infertilitesi, bir erkeğin en az bir y1l korunmasız cinsel ilişkide bulunarak doğurgan bir kadında gebelik oluşturamaması olarak tanımlanır. Erkek infertilitesi, vakaların yaklaşık \%20'sinden tek başına sorumludur ve tüm infertilite vakalarının \%30 ila \%40'ına katkıda bulunan bir faktördür. Genel olarak, erkek faktörü, tüm infertilite vakalarının yaklaşık \%50'sinde önemli ölçüde katkıda bulunur (1). Dünya çapında yaklaşık 30 milyon erkek infertildir ve çoğunluğu Orta-Doğu Avrupa'da ve Avustralya'da görülmektedir (2).

Erkek infertilitesi etiyolojisinde; kriptorşidizm, varikosel, endokrinolojik bozukluklar, seminal yolların tıkanması / yokluğu, enfeksiyonlar, alkol tüketimi, kemoterapi gibi çeşitli faktörler sayılabilir. Bununla birlikte, genetik değişiklikler de erkek infertilitesinin önde gelen nedenlerinden biri olarak ortaya çıkmıştır. İnfertil erkeklerde yaygın olarak görülen genetik kusurlar arasında kromozomal anormallikler, gen kopya sayısı varyasyonları (CNV'ler), tek gen mutasyonları / polimorfizmleri ve Y kromozomunun uzun kolundaki delesyonlar (Yq mikrodelesyonları) bulunur. Bu genetik kusurlar, gelişim sırasında erkek gonadların veya ürogenital sistemin gelişimini engeller, germ hücresi üretiminin durmasına ve / veya olgunlaşmamasına neden olur veya fonksiyonel olmayan spermler üretir. Kromozomal anormallikler ve $\mathrm{Y}$ kromozomu mikrodelesyonları erkek infertilitesinin önde gelen genetik nedenlerindendir (3).

Kromozomal anomaliler, erkek infertilitesinin sık görülen nedenlerinden biri olarak bilinmektedir ve insidansının azospermik erkeklerde \%20'lere kadar yüksek olduğu gösterilmiştir ve daha yaygı̀n olarak cinsiyet kromozomları anormalliklerini içermektedir. Diğer yandan, şiddetli oligozoospermili infertil erkeklerin \%8'ine kadarında, çoğunluğu robertsonian translokasyonlar, dengeli translokasyonlar, inversiyonlar (perisentrik veya parasentrik) gibi otozomal kromozomlardaki yapısal değişiklikler olan bir veya daha fazla kromozomal anormallikler bulunmuştur (4).

Erkek infertilitesine yol açan bir diğer genetik neden $\mathrm{Y}$ kromozomu mikrodelesyonlarıdır. Y kromozomunun (Yq) uzun kolundaki bir genomik bölgenin spermatogenezindeki anahtar rolü kırk yılı aşkın süredir bilinmektedir. Farklı çalışmalar, Yq'nin birkaç terminal ve interstisyel mikrodelesyonunun sperm sayısını ve morfolojisini etkileyerek infertilite ile ilişkili olduğunu ve azospermi faktörü (AZF) a, b ve c olarak adlandırılan (proksimal, orta ve distal Yq11 alt bölgelerinde bulunan) üç farklı aralığı tanımladığını bildirmişlerdir (5).

$\mathrm{Bu}$ çalışmamızda, hastanemize infertilite nedeniyle başvuran erkeklere yardımcı üreme tekniklerinden önce uygun genetik danışmanlık verebilmek için, azospermi ve/veya oligozoospermi etiyolojisine yönelik standart sitogenetik yöntemler ve Y kromozom mikrodelesyon analizleri ile incelenerek hem majör kromozom anomalilerinin hem de y kromozomu mikrodelesyonlarının sıklığı ve tiplerinin araştırılması amaçlanmıştır.

\section{GEREÇ VE YÖNTEMLER}

Çalışmamıza 2017-2020 yılları arasında erkek infertilitesi nedeniyle Kanuni Sultan Süleyman Eğitim ve Araştırma hastanemize başvuran, Üroloji kliniğimizde değerlendirilen, spermiogram analizleri yapılan ve sonucunda anormallik saptanarak Tibbi genetik polikliniğimize genetik açıdan değerlendirilmek üzere yönlendirilen 437 hasta dahil edildi. Çalışmamız Helsinki bildirgesine uygun olarak yapıldı ve Kanuni Sultan Süleyman Eğitim ve Araştırma Hastanesi Etik Kurul'u tarafindan da etik kurul onayı aldı (KAEK/2021.02.28).

Tüm hastalar Üroloji polikliniğinde detaylı bir fizik muayene yapıldiktan sonra semen analizleri ve hormonal tetkikleri (FSH, LH, Testosteron vb.) planlandi. Ardından Tıbbi genetik polikliniğimizde genetik analizler öncesi onam formları alındıktan sonra Kromozom analizleri ve Y-kromozom mikrodelesyon analizleri planlandi.

\section{Semen analizi}

Semen analizi Dünya Sağlık Örgütü Kılavuzu'na göre gerçekleştirildi (6). 3-7 günlük cinsel perhiz süresi sonrası alınan semen numuneleri $37^{\circ} \mathrm{C}$ de likefaksiyon işlemi gerçekleştikten sonra ilk bir saat içinde değerlendirildi. Mikroskobik değerlendirme Makler sayım kamarası (Sefi Medikal Ltd, İsrail, Haifa) ve faz kontrast 1 şı mikroskobu (Olympus BX51, Japonya) kullanılarak yapıldı. Sperm konsantrasyonu, sperm sayısı ve hareket oranları değerlendirildi. Azospermi olarak değerlendirilen hastaların semen örnekleri 2000 rpm'de 15 dk santrifüj sonrasi pelletten hazırlanan lam yayma preparatlarda değerlendirildi. Semen örneklerinden santrifüj sonras1 sperm tespit edilen vakalar kriptozoospermi olarak değerlendirildi. Sperm konsantrasyonu $<15 \mathrm{mil} / \mathrm{ml}$ olan örnekler oligozoospermi olarak sinıflandırıldı. Oligozoospermik hastalar üç alt kategoride değerlendirildi. (Şiddetli: $<5 \mathrm{mil} / \mathrm{ml}$, orta şiddetli: 5-10 $\mathrm{mil} / \mathrm{ml}$, hafif: $10-15 \mathrm{mil} / \mathrm{ml})$. İleri hareketli spermlerin oran1 $<\% 32$ olan olgular astenozoospermi olarak değerlendirildi. Sperm konsantrasyonu $>15 \mathrm{mil} / \mathrm{ml}$ olan ve ileri hareketli spermlerin oranı $>\% 32$ olan örnekler normozoospermi olarak değerlendirildi.

\section{Kromozom analizi}

Hastaların periferik kan lenfositlerinde $G$ bantlama yapılarak kromozom analizleri yapıldı. Hastaların kanları heparinli tüplere alındı. Kültürler $\mathrm{Pb}$-Max ortamında 72 saat $37^{\circ} \mathrm{C}$ 'de inkübe edildi. $40 \mathrm{mg} / \mathrm{ml}$ kolşisin ile 2 saat muamele edildi. Hipotonik şok $(0,075 \mathrm{M} \mathrm{KCl})$, fiksasyon ve Leishmann boyama ile metafaz kromozomların Gbantlaması yapıldı. Her hasta için en az 20 metafaz plağ analiz edildi. Saptanan kromozom anomalileri Uluslararası İnsan Sitogenomik İsimlendirme Sistemine (ISCN 2016) göre tanımlandı.

\section{Y kromozomu mikrodelesyon analizi}

Invitrogen PureLink Genomic DNA Mini Kit kullanılarak çalışmaya dahil edilen hastaların periferik kanlarından DNA izolasyonları yapıldı. GML Y Chromosome Deletion Extensive Kiti ile her olgunun AZFa, AZFb ve 
AZFc bölgelerinde yer alan markerlar, Applied Biosystems Veriti 96-Well Thermal Cycler cihazında multiplex PCR yöntemi ile amplifiye edildi. PCR ürünleri Applied Biosystems 3500 Genetic Analyzer cihazına yüklendi. Veriler GeneMapper Software 6 yazılımı ile değerlendirildi.

\section{İstatistiksel analiz}

İstatistiksel analizler IBM SPSS Statistics for Windows, sürüm 23.0 (IBM Corp., Armonk, New York, ABD) aracılığıyla gerçekleştirildi. Veriler ortalama \pm standart sapma, minimum-maksimum ve yüzde olarak ifade edildi. Verilerin temel özelliklerini tanımlamak için tanımlayıcı istatistikler ve nitel değişkenler için Ki-kare testi yapılmıştır. Tüm sonuçlar $\mathrm{p}<0,05$ düzeyinde istatistiksel olarak anlamlı kabul edildi.

Tablo 1. Kromozom analizi sonuçları

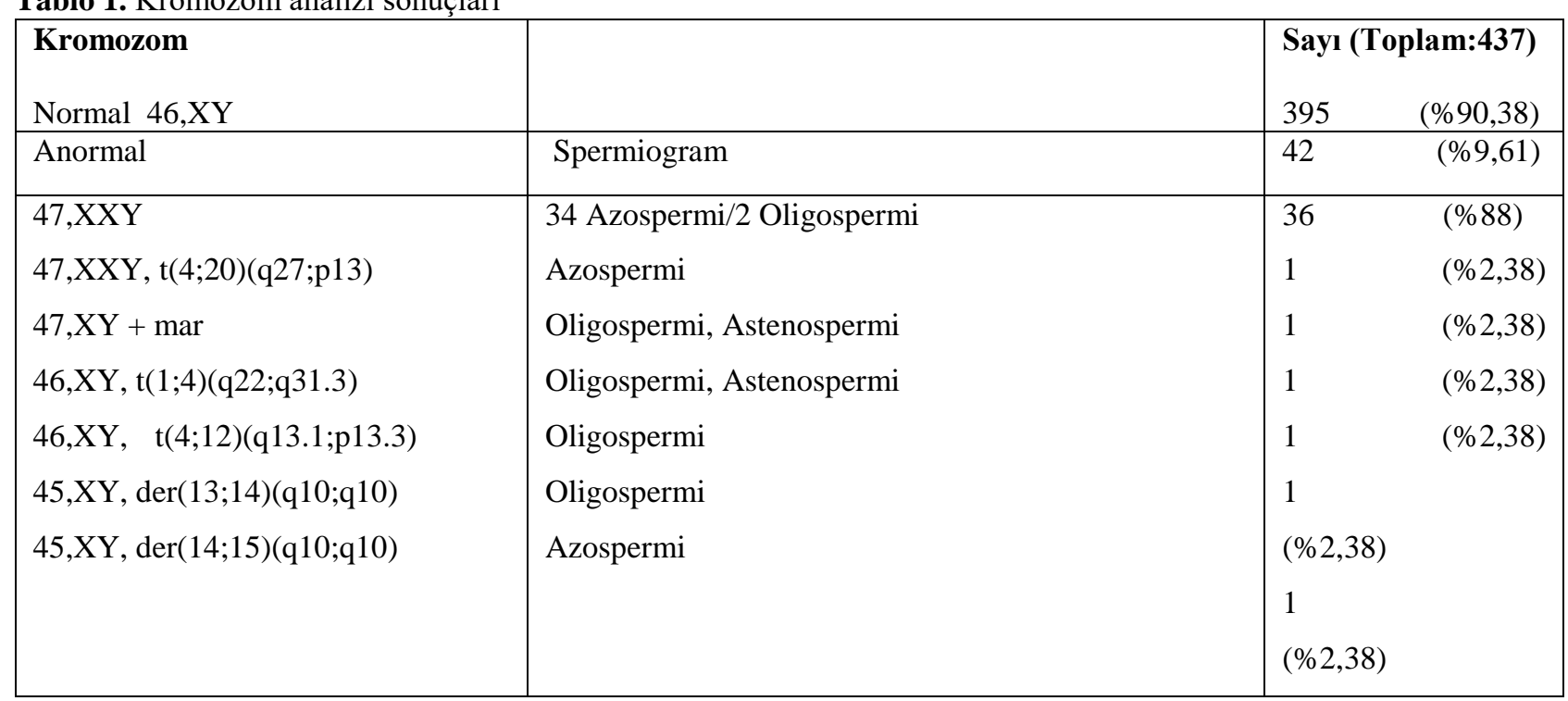

Y kromozomu mikrodelesyon analizi sonuçlarına göre ise toplam 44 hastada AZF bölgelerinde çeşitli delesyonlar görüldü. $1(\% 0,2)$ hastada $\mathrm{AZFa}$ delesyonu, $4(\% 0,9)$ hastada $\mathrm{AZFb}+\mathrm{c}$ delesyonu, $17(\% 3,9)$ hastada AZF-c (sy1291) $\mathrm{gr} / \mathrm{gr}$ delesyonu, $2(\% 0,5)$ hastada komplet $\mathrm{AZFa}+\mathrm{b}+\mathrm{c}$ delesyonu, $2(\% 0,5)$ hastada komplet AZFc delesyonu, $1(\% 0,2)$ hastada parsiyel AZFb delesyonu, 9 $(\% 2,1)$ hastada kısmi AZFb+c delesyonu, $8(\% 1,8)$ hastada

\section{BULGULAR}

Çalıșmaya dahil edilen toplam 437 hastanın; 2'sinde $(\% 0,5)$ kuru ejakülat (aspermi), 185'inde (\%42,3) azospermi, 9'unda $(\% 2,1)$ normospermi, 39'unda $(\% 8,9)$ orta derecede oligospermi, 11 'inde $(\% 2,5)$ orta oligoastenospermi, 43'ünde $(\% 9,8)$ şiddetli oligospermi, 109'unda $(\% 24,9)$ şiddetli oligo-astenospermi vardı. 39 hastanın spermiogram sonuçlarına ulaşılamadı.

Hastaların ortalama yaşları 32,222 $\pm 6,106$ (min: 18, maks: $58)$ idi. Toplam $50(\% 11,4)$ kişide orta derecede oligospermi varken, $152 \quad(\% 34,8)$ kişide şiddetli oligospermi vardı. Ayrıca tüm hastalar arasında toplam $120(\% 27,5)$ astenospermi ve $82(\% 18,8)$ astenospermi olmayan hasta olduğu tespit edildi.

Hastaların \%9,6'sında (42/437) kromozomal anomaliler tespit edildi. Kromozom analizi sonuçlarına göre hastalarda tespit edilen kromozomal anomaliler Tablo 1'de özetlenmiştir. parsiyel AZFc delesyonu tespit edildi. Geriye kalan 393 $(\% 89,9)$ hastada herhangi bir Y kromozomu mikrodelesyonu saptanmadis $\quad$ Y-kromozom mikrodelesyonu saptanan hastaların spermiogram bulguları, hormonal profili ve kromozom analizi sonuçları Tablo 2'de özetlenmiştir. Klinefelter(47,XXY) tanısı alan 3 hastamızda da AZF delesyonları görüldü. 
Tablo 2. Y-Kromozomu Mikrodelesyonu Saptanan Hastalar Ve Spermiogram, Hormonal Profil Ve Kromozom Analizi Sonuçları

\begin{tabular}{|c|c|c|c|}
\hline Spermiogram & Hormonal Profil & Karyotip & Y-mikro delesyon analizi \\
\hline Azospermi & Hipergonadotropik & $46, X Y$ & AZFa delesyonu \\
\hline Azospermi & Normogonadotropik & $46, X Y$ & $\mathrm{AZFb}+\mathrm{c}$ delesyonu \\
\hline Azospermi & Normogonadotropik & $46, X Y$ & $\mathrm{AZFb}+\mathrm{c}$ delesyonu \\
\hline Azospermi & Normogonadotropik & $46, X Y$ & $\mathrm{AZFb}+\mathrm{c}$ delesyonu \\
\hline Azospermi & Hipergonadotropik & $47, \mathrm{XXY}$ & $\mathrm{AZFb}+\mathrm{c}$ delesyonu \\
\hline Oligospermi (Şiddetli), Astenospermi & Normogonadotropik & $46, X Y$ & AZFc gr/gr delesyonu \\
\hline Oligospermi (Şiddetli), Astenospermi & Normogonadotropik & $46, X Y$ & AZFc gr/gr delesyonu \\
\hline Oligospermi (Şiddetli), Astenospermi & Hipogonadotropik & $46, X Y$ & AZFc gr/gr delesyonu \\
\hline Azospermi & Hipergonadotropik & $46, X Y$ & AZFc gr/gr delesyonu \\
\hline Oligospermi (Şiddetli), Astenospermi & Normogonadotropik & $46, X Y$ & AZFc gr/gr delesyonu \\
\hline Azospermi & Hipergonadotropik & $47, \mathrm{XXY}$ & AZFc gr/gr delesyonu \\
\hline Oligospermi (Şiddetli), Astenospermi & Normogonadotropik & $46, X Y$ & AZFc gr/gr delesyonu \\
\hline Oligospermi (Orta) & Normogonadotropik & $46, X Y$ & AZFc gr/gr delesyonu \\
\hline Oligospermi (Şiddetli) & Normogonadotropik & $46, X Y$ & AZFc gr/gr delesyonu \\
\hline Azospermi & Normogonadotropik & $46, X Y$ & AZFc gr/gr delesyonu \\
\hline Azospermi & Normogonadotropik & $46, X Y$ & AZFc gr/gr delesyonu \\
\hline Azospermi & Hipergonadotropik & $47, \mathrm{XXY}$ & AZFc gr/gr delesyonu \\
\hline Oligospermi (Şiddetli) & Normogonadotropik & $46, X Y$ & AZFc gr/gr delesyonu \\
\hline Oligospermi (Şiddetli), Astenospermi & Normogonadotropik & $46, X Y$ & AZFc gr/gr delesyonu \\
\hline Azospermi & Normogonadotropik & $46, X Y$ & AZFc gr/gr delesyonu \\
\hline Azospermi & Normogonadotropik & $46, X Y$ & AZFc gr/gr delesyonu \\
\hline Azospermi & Normogonadotropik & $46, X Y$ & AZFc gr/gr delesyonu \\
\hline Azospermi & Normogonadotropik & $46, X Y$ & Komplet $\mathrm{AZFa}+\mathrm{b}+\mathrm{c}$ delesyonu \\
\hline Azospermi & Hipergonadotropik & $46, X Y$ & Komplet $\mathrm{AZFa}+\mathrm{b}+\mathrm{c}$ delesyonu \\
\hline Azospermi & Normogonadotropik & $46, X Y$ & Komplet AZFc delesyonu \\
\hline Azospermi & Normogonadotropik & $46, X Y$ & Komplet AZFc delesyonu \\
\hline Oligospermi (Şiddetli), Astenospermi & Normogonadotropik & $46, X Y$ & Parsiyel AZFb delesyonu \\
\hline Azospermi & Hipergonadotropik & $46, X Y$ & Parsiyel $\mathrm{AZFb}+\mathrm{c}$ delesyonu \\
\hline Oligospermi (Şiddetli), Astenospermi & Normogonadotropik & $46, X Y$ & Parsiyel AZFb+c delesyonu \\
\hline Azospermi & Hipergonadotropik & $46, X Y$ & Parsiyel $\mathrm{AZFb}+\mathrm{c}$ delesyonu \\
\hline Oligospermi (Şiddetli), Astenospermi & Normogonadotropik & $46, X Y$ & Parsiyel $\mathrm{AZFb}+\mathrm{c}$ delesyonu \\
\hline Oligospermi (Şiddetli), Astenospermi & Normogonadotropik & $46, X Y$ & Parsiyel $\mathrm{AZFb}+\mathrm{c}$ delesyonu \\
\hline Oligospermi (Şiddetli) & Hipergonadotropik & $46, X Y$ & Parsiyel $\mathrm{AZFb}+\mathrm{c}$ delesyonu \\
\hline Azospermi & Hipergonadotropik & $46, X Y$ & Parsiyel $\mathrm{AZFb}+\mathrm{c}$ delesyonu \\
\hline Azospermi & Normogonadotropik & $46, X Y$ & Parsiyel $\mathrm{AZFb}+\mathrm{c}$ delesyonu \\
\hline Oligospermi (Şiddetli), Astenospermi & Normogonadotropik & $46, X Y$ & Parsiyel $\mathrm{AZFb}+\mathrm{c}$ delesyonu \\
\hline Oligospermi (Şiddetli), Astenospermi & Normogonadotropik & $46, X Y$ & Parsiyel AZFc delesyonu \\
\hline Azospermi & Normogonadotropik & $46, X Y$ & Parsiyel AZFc delesyonu \\
\hline Azospermi & Hipergonadotropik & $46, X Y$ & Parsiyel AZFc delesyonu \\
\hline Azospermi & Hipergonadotropik & $46, X Y$ & Parsiyel AZFc delesyonu \\
\hline Oligospermi (Orta), Astenospermi & Normogonadotropik & $46, X Y$ & Parsiyel AZFc delesyonu \\
\hline Oligospermi (Şiddetli), Astenospermi & Normogonadotropik & $46, X Y$ & Parsiyel AZFc delesyonu \\
\hline Azospermi & Normogonadotropik & $46, X Y$ & Parsiyel AZFc delesyonu \\
\hline Oligospermi (Şiddetli), Astenospermi & Normogonadotropik & $46, X Y$ & Parsiyel AZFc delesyonu \\
\hline
\end{tabular}




\section{TARTIŞMA}

Nonobstrüktif azospermi olan erkeklerin yaklaşık \%15'i ve orta derecede oligozoospermi ( $\mathrm{ml}$ başına $<10$ milyon spermatozoa) olan erkeklerin yaklaşı $\%$ 4'ünde kromozomal anomaliler mevcut olduğundan, spermiogram anormalliği olan infertil hastalarda yapılması gereken ilk genetik test kromozom analizidir (7). Hastalarımızın \%9,6'sında (42/437) kromozomal anomaliler tespit edildi. En sik kromozomal anomali ve Ykromozom mikrodelesyonu azospermi hastalarında görüldü. Spermiogram konsantrasyonu ile kromozomal anomali ve Y-kromozom mikrodelesyonları korelasyonu görülmektedir (Tablo 3a). Literatür incelendiğinde infertil erkekler arasındaki kromozomal anomalilerin sıklı̆̆ çalışılan hasta sayısı, spermiogram bulguları, coğrafi bölge ve etnik kökene göre değişkenlikler göstermektedir. Türk hastalar ile yapılan çalışmalarda ortalama kromozomal anomali sıklığı \%4,8 ile \%11,2 arasındaydı (8-10). Bizim çalışmamızda da bu oran literatür ile uyumlu bulundu. Kromozomal anomaliler azospermili hastalarda diğer sperm anormalliklerine oranla çok daha fazla oranda görüldü. En sık gözlenen kromozomal anomali yine literatürle uyumlu olarak 47, XXY- Klinefelter sendromu $(\% 8,4)$ oldu. Toplam 37 hastada Klinefelter sendromu tespit edildi. $\mathrm{Bu}$ hastalar arasından bir hastada ekstra dengeli translokasyon da vardı. 4 hastamızda ayrıca farklı translokasyonlar mevcuttu (Tablo-1). Dengeli translokasyonların genelde bireyin fenotipine etki etmemesi beklenirken burada kromozomal kırık bölgelerinde meydana gelen submikroskobik genetik değişimlerin spermatogenezi etkileyebileceği düşünülmektedir (11). Bizimde translokasyon tespit ettiğimiz 5 hastamızın 1 'inde aynı zamanda 47,XXY mevcuttu ve bu hastamiz azospermikti. Geriye kalan 4 hastamizdan 3'ünde oligospermi ve 1'inde azospermi mevcuttu.

Amerikan Üreme Tibb1 Derneği'nin Uygulama Komitesi'ne göre, Y-kromozomu mikrodelesyonlarının prevalans1, erkeklerde genel popülasyonunda \%2'ye kadar çıkabilmektedir (12). Avrupa Androloji Akademisine göre ise bu oran çok daha düşük olarak yaklaşık 4000'de 1 $(\% 0,025)$ olarak değerlendirilmektedir (13). 10.000'den fazla Kuzey Amerikalı erkeğin incelendiği bir metaanalizde, şiddetli oligospermik hastaların \%5'inde Ykromozomu mikrodelesyonu tespit edilirken, normospermik olan erkeklerde bu oran \%1'den az olarak bulunmuştur (14). İnfertil erkek popülasyonları içinde Ykromozomu mikrodelesyonlarının bildirilen sıklıklarına bakılınca, coğrafi bölge ve etnik kökene göre birbirinden oldukça farklılıklar göstermektedir. İnfertil erkeklerde AZF delesyonlarının dünya çapındaki sıklık tahminleri, Amerika Birleşik Devletleri'nde \%12 ve İran'da \%24,2'den Almanya ve Avusturya gibi ülkelerde \%2'nin altına kadar değişmektedir (15). Çalışılan hasta popülasyonunun büyüklüğü, spermatogenez kusurlarının etiyolojisi ve ciddiyetine göre hasta seçimi ve bölgesel farklılıklar infertilite ile ilgili kromozomal anomaliler ve $\mathrm{Y}$ kromozomu mikrodelesyonlarının değişken oranlarda bulunmasının olası nedenleri olarak kabul edilebilir.

İnertil ve subfertil erkekleri altta yatan bir Y kromozom mikrodelesyonunun varlığını belirlemek için taramanın klinik ortamda hayati olduğu yapılan çalışmalarla doğrulanmıştır, çünkü bu tür delesyonların kapsamı genellikle klinik karar verme ve yardımcı üreme teknolojileri için tavsiyelerde bulunur. AZFc delesyonları en sık görülen $\mathrm{Y}$ kromozom mikrodelesyonudur ve bildirilen tüm delesyonların \%60-80'ini oluşturur (13).

Toplam 437 hastamızın 44'ünde $(\% 10,06)$ Y-kromozomu mikrodelesyonları tespit edilmişti. Bizim de çalışmamızda en sık görülen Y-kromozomu mikrodelesyon bölgesi AZFc delesyonlarıydı. Toplam 27 hastamızda çeşitli derecelerde AZFc delesyonu tespit edildi. Bunlar arasında en sık görülen 17 hasta ile gr/gr delesyonuydu. AZFc bölgesi içindeki klinik olarak en ilişkili olanı hem sıklığı hem de bu delesyona ilişkin verilerin çokluğu açısından gr/gr delesyonudur (13). Bu delesyon, AZFc bölgesi gen içeriğinin yarısını ortadan kaldırarak bu bölge içinde haritalanan çok kopyalı genlerin dozajını etkiler (DAZ, CDY1 ve BPY2 gibi). Bu delesyona sahip erkekler, oligozoospermiye yakalanma açısından önemli ölçüde artmış risk altındadır, aynı ülkelerden infertil İtalyan ve İspanyol erkekleri ve normozoospermik erkekleri içeren bir çalışmanın sonuçları, gr / gr delesyon taşıyıcılarının, bu genetik anomalisi olmayan erkeklere kıyasla oligozoospermiye yakalanma riskinin dört kat arttı̆̆ını göstermiştir (16). Bizim çalışmamızda da gr/gr delesyonu saptanan hastalarımızın 9'unda oligospermi, 8'inde ise azospermi bulundu.

Çalışmamızda 1 hastamızda komplet AZFa delesyonu, 4 hastada komplet $\mathrm{AZFb}+\mathrm{c}$ delesyonu, 2 hastada komplet $\mathrm{AZFa}+\mathrm{b}+\mathrm{c}$ delesyonu, 2 hastada komplet $\mathrm{AZFc}$ delesyonu vardı. Tüm bu 9 hastanın ortak özelliği hepsinde azospermi görülmesiydi. Çalışmamızda parsiyel delesyonlar da saptand1. 1 hastada parsiyel AZFb delesyonu, 9 hastada parsiyel $\mathrm{AZFb}+\mathrm{c}$ delesyonu, 8 hastada parsiyel $\mathrm{AZFc}$ delesyonu vardı. Bu hastaların spermiogramları arasında da değişkenlik vardı (Tablo 2).

Çalışmamızda sperm hareketliliği açısından değerlendirilebilen 120 hastanın spermiogramında astenospermi vard1. 82 hasta ise normal olarak değerlendirildi. Astenospermi olan hastalarda kromozomal anomali sıklığı \%1,7 iken bu oran diğer grupta \%4,9 olarak bulundu. Y-kromozom mikrodelesyonları açısından incelendiğinde astenospermi olan hastalarda \%12,5 oranında mikrodelesyon görülürken diğer grupta bu oran $\% 6,1$ di. $\mathrm{Bu}$ iki grup arasında kromozomal anomali ve Y mikro delesyonu açısından anlamlı bir farklılık görülmedi (Tablo 3b).

Hormonal profillere göre hastalar incelendiğinde ise en yüksek kromozomal anomali ve Y-kromozomu mikrodelesyonu hipergonadotropik hipogonadizm olan grupta görüldü (Tablo-3c). 
Tablo 3.

a: Hastaların Hem Kromozom Analizi Hem de Y-Mikrodelesyon Analizi Sonuçları İle Spermiogram Analiz Sonuçlarının Karşılaştırılması

\begin{tabular}{|c|c|c|c|c|c|c|c|}
\hline & \multicolumn{2}{|c|}{ Karyotip } & $\chi^{2} / \mathrm{p}$ & \multicolumn{2}{|c|}{ Y-mikrodelesyon } & \multicolumn{2}{|l|}{$\chi^{2} / \mathrm{p}$} \\
\hline & $\begin{array}{l}\text { Normal } \\
(46, X Y)\end{array}$ & Anormal & \multirow{7}{*}{$\begin{array}{l}36.307 / \\
0.000\end{array}$} & Normal & Anormal & \multirow{7}{*}{$\begin{array}{l}9,883 \\
0,079\end{array}$} & \\
\hline Azospermi & $149(37,7 \%)$ & $36(87,5 \%)$ & & $161(41 \%)$ & $24(54,5 \%)$ & & \\
\hline $\begin{array}{l}\text { Orta derecede oligospermi }+ \\
\text { orta } \\
\text { oligoastenospermi }\end{array}$ & $48(12,2 \%)$ & $2(4,8 \%)$ & & $48(12,2 \%)$ & $2(4,8 \%)$ & & \\
\hline $\begin{array}{l}\text { Şiddetli oligospermi } \\
\text { şiddetli oligoastenospermi }\end{array}$ & $148(37,5 \%)$ & $4(9,5 \%)$ & & $134(34,1 \%)$ & $18(40,9 \%)$ & & \\
\hline Aspermi & $2(0,5 \%)$ & $0(0 \%)$ & & $2(0,5 \%)$ & $0(0 \%)$ & & \\
\hline Normospermi & $9(2,3 \%)$ & $0(0 \%)$ & & $9(2,3 \%)$ & $0(0 \%)$ & & \\
\hline Yok & $39(9,9 \%)$ & $0(0 \%)$ & & $39(9,9 \%)$ & $0(0 \%)$ & & \\
\hline
\end{tabular}

b: Hem Kromozomal Analiz Hem de Y-Mikrodelesyon Analizi Sonuçlarına Göre Astenospermi Olan Veya Olmayan Bireylerin Karşılaştırılması

\begin{tabular}{|c|c|c|c|c|c|c|c|}
\hline & Karyotip & & $\chi^{2} / p$ & Y-mikr & elesyon & $\chi^{2} / p$ & \\
\hline & $\begin{array}{l}\text { Normal } \\
(46, X Y)\end{array}$ & Anormal & \multirow{3}{*}{$\begin{array}{l}1.743 / \\
0.187\end{array}$} & Normal & Anormal & \multirow{3}{*}{$\begin{array}{l}2,238 \\
0,135\end{array}$} & \multirow{3}{*}{ / } \\
\hline Astenospermi olan & $118(98,3 \%)$ & $2(1,7 \%)$ & & $105(87,5 \%)$ & $15(12,5 \%)$ & & \\
\hline Astenospermi olmayan & $78(95,1 \%)$ & $4(4,9 \%)$ & & $77(93,9 \%)$ & $5(6,1 \%)$ & & \\
\hline
\end{tabular}

c: Hastaların Hem Kromozomal Analizi Hem de Y-Mikrodelesyon Analizi Sonuçlarının Hormonal Profilleri İle Karşılaştırılması

\begin{tabular}{|c|c|c|c|c|c|c|}
\hline & Karyotip & & $\chi^{2} / \mathrm{p}$ & \multicolumn{2}{|c|}{ Y-mikrodelesyon } & $\chi^{2} / \mathrm{p}$ \\
\hline & $\begin{array}{l}\text { Normal } \\
(46, X Y)\end{array}$ & Anormal & \multirow{4}{*}{$\begin{array}{l}41.639 / \\
0.000\end{array}$} & Normal & Anormal & \multirow{4}{*}{$\begin{array}{l}0,266 \\
/ \\
0,876\end{array}$} \\
\hline $\begin{array}{l}\text { Hipergonadotropik } \\
\text { hipogonadizm }\end{array}$ & $80(74,8 \%)$ & $27(25,2 \%)$ & & $95(88,8 \%)$ & $12(11,2 \%)$ & \\
\hline $\begin{array}{l}\text { Hipogonadotropik } \\
\text { hipogonadizm }\end{array}$ & $11(84,6 \%)$ & $2(15,4 \%)$ & & $12(92,3 \%)$ & $1(7,7 \%)$ & \\
\hline Normogonadotropik & $304(95,6 \%)$ & $13(4,1 \%)$ & & $286(90,2 \%)$ & $31(9,8 \%)$ & \\
\hline
\end{tabular}

Y-kromozom mikrodelesyonuna sahip erkeklerde, başarılı sperm elde etme oranı büyük ölçüde etkilenen AZF bölgesine bağlıdır. AZFc bölgesindeki delesyonlar, en yüksek sperm elde etme şansına sahiptir ve çalışmalarda $\% 50$ ile $\% 80$ arasında bildirilmiştir $(17,18)$. AZFa ve $\mathrm{AZFb}$ bölgelerinde tespit edilen mikrodelesyonlar ise son derece olumsuz sperm elde etme oranları ve klinik sonuçlarla ilişkilendirilmiştir. Ayrıca, AZFbc ve AZFabc gibi birden fazla AZF bölgesinin bölümlerini içeren delesyonlar da zayıf sperm elde etme oranları ile ilişkilendirilmiştir (19).

AZFc delesyonları içeren erkekler, genetik taramanın ardından yardımcı üreme tekniklerine yönlendirilirken önemli bir konuda AZFc delesyonu olan bir erkeğin herhangi bir erkek çocuğu, babasının mikrodelesyonlu Y kromozomunu miras alacaktır. Bu nedenle doğacak erkek çocuklar babalarından eşit derecede veya daha şiddetli infertilite kliniğine sahip olabilir (20). Hastalara bu konuda ayrıntılı genetik danışmanlığın da verilmesi çok önemlidir.

\section{SONUÇ}

Sonuç olarak yapılan tüm çalışmalar özellikle şiddetli oligospermi ve azospermi ile başvuran infertil erkek hastalarda yardımcı üreme tekniklerine geçmeden önce kromozom analizi ve $\mathrm{Y}$ mikrodelesyon analizlerinin yapılmasını önermektedir. Bizim çalışmamızda da literatür ile benzer olarak özellikle şiddetli oligospermi ve azospermi varlığında kromozomal anomali ve Ykromozomu mikrodelesyonlarının oranının arttığı görüldü. Özellikle infertilite ile başvuran erkek hastalarda kromozom analizi ve Y-kromozom mikrodelesyonu ile inceleme hangi hastanın yardımcı üreme tekniğine yönlendirileceği ve sperm elde etmede testiküler sperm ekstraksiyonu (TESE) gibi hangi yöntemin seçilmesi gerektiği hakkında önemli bulgular verebilir. Ayrıca hastalara uygun genetik danışmanlık imkânı da sunar.

Yazar katkıları: Fikir/Kavram: A.G.; Tasarım: A.G.; Veri Toplama: A.G., I.Ü., E.Y.G., İ.O.A., G.Ç.; Analiz ve Yorum: A.G., R.E.; Literatür Taraması: A.G.; Makale Yazımı: A.G., I.Ü.; Eleştirel İnceleme: R.E. 


\section{KAYNAKLAR}

1. Leslie SW, Siref LE, Soon-Sutton TL, Khan MAB. Male Infertility. StatPearls. Treasure Island (FL) 2021.

2. Agarwal A, Mulgund A, Hamada A, Chyatte MR. A unique view on male infertility around the globe. Reprod Biol Endocrinol. 2015; 13: 37.

3. Colaco S, Modi D. Genetics of the human Y chromosome and its association with male infertility. Reprod Biol Endocrinol. 2018; 16(1): 14.

4. Fu L, Xiong DK, Ding XP, Li C, Zhang LY, Ding M, et al. Genetic screening for chromosomal abnormalities and Y chromosome microdeletions in Chinese infertile men. J Assist Reprod Genet. 2012; 29(6): 521-7.

5. Cervan-Martin M, Castilla JA, Palomino-Morales RJ, Carmona FD. Genetic Landscape of Nonobstructive Azoospermia and New Perspectives for the Clinic. J Clin Med. 2020; 9(2): 300.

6. Sanchez-Alvarez J, Cano-Corres R, Fuentes-Arderiu X. A Complement for the WHO Laboratory Manual for the Examination and Processing of Human Semen (First Edition, 2010). EJIFCC. 2012; 23(3): 103-6.

7. Krausz C, Riera-Escamilla A. Genetics of male infertility. Nat Rev Urol. 2018; 15(6): 369-84.

8. Akin H, Onay H, Turker E, Ozkinay F. Primary male infertility in Izmir/Turkey: a cytogenetic and molecular study of 187 infertile Turkish patients. J Assist Reprod Genet. 2011; 28(5): 419-23.

9. Ozdemir TR, Ozyilmaz B, Cakmak O, Kaya OO, Kose $\mathrm{C}$, Kirbiyik O, et al. Evaluation of chromosomal abnormalities and Y-chromosome microdeletions in 1696 Turkish cases with primary male infertility: A single-center study. Turk J Urol. 2020; 46(2): 95-100.

10. Balkan M, Tekes S, Gedik A. Cytogenetic and Y chromosome microdeletion screening studies in infertile males with Oligozoospermia and Azoospermia in Southeast Turkey. J Assist Reprod Genet. 2008; 25(11-12): 559-65.

11. Zhang H, Wang R, Li L, Jiang Y, Zhang H, Liu R. Clinical feature of infertile men carrying balanced translocations involving chromosome 10: Case series and a review of the literature. Medicine (Baltimore). 2018; 97(15): e0452.

12. Practice Committee of the American Society for Reproductive M. Diagnostic evaluation of the infertile male: a committee opinion. Fertil Steril. 2015; 103(3): e18-25.

13. Krausz C, Hoefsloot L, Simoni M, Tuttelmann F, European Academy of A, European Molecular Genetics Quality N. EAA/EMQN best practice guidelines for molecular diagnosis of Y-chromosomal microdeletions: state-of-the-art 2013. Andrology. 2014; 2(1): 5-19.

14. Kohn TP, Kohn JR, Owen RC, Coward RM. The Prevalence of Y-chromosome Microdeletions in Oligozoospermic Men: A Systematic Review and Meta-analysis of European and North American Studies. Eur Urol. 2019; 76(5): 626-36.

15. Simoni M, Tuttelmann F, Gromoll J, Nieschlag E. Clinical consequences of microdeletions of the $\mathrm{Y}$ chromosome: the extended Munster experience. Reprod Biomed Online. 2008; 16(2): 289-303.

16. Krausz C, Casamonti E. Spermatogenic failure and the Y chromosome. Hum Genet. 2017; 136(5): 637-55.
17. Park SH, Lee HS, Choe JH, Lee JS, Seo JT. Success rate of microsurgical multiple testicular sperm extraction and sperm presence in the ejaculate in korean men with y chromosome microdeletions. Korean J Urol. 2013; 54(8): 536-40.

18. Silber SJ. The Y chromosome in the era of intracytoplasmic sperm injection: a personal review. Fertil Steril. 2011; 95(8): 2439-48 e1-5.

19. Arshad MA, Majzoub A, Esteves SC. Predictors of surgical sperm retrieval in non-obstructive azoospermia: summary of current literature. Int Urol Nephrol. 2020; 52(11): 2015-38.

20. Cariati F, D'Argenio V, Tomaiuolo R. The evolving role of genetic tests in reproductive medicine. J Transl Med. 2019; 17(1): 267. 